\title{
Anti-EGFR Monoclonal Antibody
}

National Cancer Institute

\section{Source}

National Cancer Institute. Anti-EGFR Monoclonal Antibody. NCI Thesaurus. Code C133878.

Any monoclonal antibody directed against epidermal growth factor receptor (EGFR). 